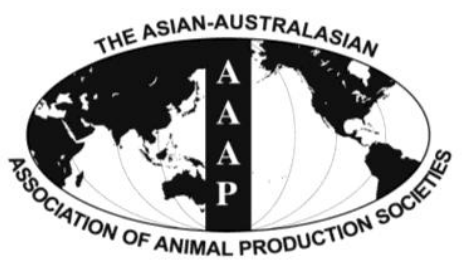

Asian-Aust. J. Anim. Sci.

Vol. 25, No. 9 : 1255 - 1261

September 2012

www.ajas.info

http://dx.doi.org/10.5713/ajas.2011.11312

\title{
Effects of Probiotic and Prebiotic on Average Daily Gain, Fecal Shedding of Escherichia Coli, and Immune System Status in Newborn Female Calves
}

\author{
Pezhman Mohamadi Roodposhti* and Najafgholi Dabiri \\ Department of Animal Science, Karaj Branch, Islamic Azad University, Karaj, Iran
}

\begin{abstract}
Thirty two Holstein female calves (initial body weight $=40 \pm 3.0 \mathrm{~kg}$ ) were used to investigate the effects of probiotic and prebiotic on average daily gain (ADG), fecal E. coli count, white blood cell count, plasma IgG1 level and cell-mediated immune response to injection of phytohemagglutinin in suckling female calves. Calves were assigned randomly to one of the four treatments, including whole milk without additives (control), whole milk containing probiotic, whole milk containing prebiotic and whole milk containing probiotic and prebiotic (synbiotic). Average daily gain was greater in calves fed probiotic, prebiotic and synbiotic at weeks 6 , 7 and 8 (p<0.05). E. coli count was significantly lower in calves fed probiotic, prebiotic and synbiotic on d 56 ( $\mathrm{p}<0.05)$. There was no significant difference between treatments in blood samples and cell-mediated response. This study showed that addition of probiotic, prebiotic and combination of these additives to milk enhanced ADG and reduced fecal E. coli count in preruminant calves. (Key Words: Holstein Calves, Multi-strain Probiotic, Mannanoligosaccharides Beta-glucan, E. coli Count, Cell-mediated Immune Response)
\end{abstract}

\section{INTRODUCTION}

Before weaning, dairy calves are susceptible to many pathogens and nutritional problems. For several years antibiotics have been used to overcome these problems also to obtain economic benefits in terms of improved calves performance and reduced medication costs. However, the use of antibiotics in animal husbandry is in question because of antibiotic resistance of microorganisms. Research shows an association between the use of subtherapeutic dose of antibiotics and antibiotic-resistance organisms (Amabile-Cuevas, 1995; Fevier et al., 1955; Piddock, 1996). In an effort to replace antibiotics from animal feeds, many additives have been proposed. Probiotic, prebiotics and combination of probiotic and prebiotic (synbiotics) are examples of these additives (Heinrich et al., 2003; Morill et al., 1995). Probiotics are live microbial feed supplements which beneficially affect the host animal by improving its microbial balance (Fuller, 1989). Probiotics have been shown to have many function, including protecting young animal against enteropathic disorders

* Corresponding Author: Pezhman Mohamadi Roodposhti. Tel: +982616601487, Fax: +982616601487, E-mail: pezhman_mrp @yahoo.com

Submitted Aug. 29, 2011; Accepted Oct. 19, 2011; Revised Jan. 24, 2012
(Windschitle et al., 1991; Timmerman et al., 2005), increasing feed efficiency and weight gain (Cruywagen et al., 1995; Lesmiester et al., 2004) and improve immune system (Yoon et al., 1995; Timmerman.et al., 2005). Although the mechanisms of action of probiotics have not been identified clearly, lactic acid bacteria are thought to inhibit the growth of pathenogenic bacteria through decreasing $\mathrm{pH}$ in large intestine by production of lactic acid and through competitive attachment (Riddell et al., 2010). Most of probiotic studies that were reported in the literatures used single or two strains probitics rather that multi strains bacteria, but Rolfe (2000) suggested that multi-strain probiotic may be more useful than a single strain because they can proliferate more lactic acid bacteria than single strain probiotic.

Prebiotics are non-digestible carbohydrates which are not metabolized in the small intestine and fermented in large intestine. Mannanoligosaccharides and $\beta$-glucan are prebiotics which derived from saccharomyeces cereviciae cell wall and are able to block fimbriae of patheno genic bacteria, and thus prevent their adhesion to the mucous epithelium (Kogan and Kocher, 2007). The administration of prebiotic to calves can decrease coliform population of large intestine and colon of calves and pigs (Miguel et al., 2004). More recently, prebiotics have been shown to have 
immune-enhancing characteristics (Okomato et al., 2003; Fleige et al., 2009). Tang et al. (2005), showed that oligosacchrides such as chitosan and galacto-manannanoligosaccharides may improve growth and feed efficiency by increasing growth hormone and insulin-like growth factor-I levels, in the early-weaned piglets. Huang et al. (2005), reported that dietary chitosan oligosaccharides supplementation was effective in increasing the ileal digestibilities of nutrients and feed efficiency in broilers. Huang et al. (2007), also reported that broilers fed diet supplemented with oligochitosan prebiotic had higher serum IgG, IgM and IgA concentration compared with broiler fed control diet. Dietary supplementation with Chinese herbal ultra-fine 3 powder as a prebiotic enhances cellular and humoral immunity in early weaned piglets (Deng et al., 2007). Kong et al. (2007), in an experiment used a Chinese herbal ultra-fine powder as a prebiotic supplementation for piglets. They reported that the powder increased ADG and feed efficiency, and reduced the incidence of diarrhea in the weaned piglets. Deng et al. (2007), reported that polysaccharides of cassiae seed can be used as a prebiotic to improve intestinal microflora. They showed that dietary inclusion of this prebiotic increased lactobacillus count, and reduced E. coli counts in digesta of ileum, cecum and colon of piglets.

The objective of the current experiment was to study the effects of feeding milk containing probiotic, prebiotic and probiotic+prebiotic (synbiotic) on average daily gain, fecal E. coli count and immune status of female suckling calves.

\section{MATERIAL AND METHODS}

\section{Animals, diets, and experimental design}

Thirty two Holstein female calves (initial body weight $=$ $40 \pm 3.0 \mathrm{~kg}$ ) were grouped based on body weight. Calves were removed from their dams and housed individually in calf house with separated pens, each of which was equipped with feeding and watering trough as required for calves. All pens were located in the same calf house and the calves were randomly allocated. The calf house was equipped with controlled ventilation and the bedding in the pens was chopped straw. Manure was removed daily and chopped straw was given to all pens again. Temperature and air humidity were monitored. Average temperature was $15.5 \pm 2.0^{\circ} \mathrm{C}$ and relative humidity was $75.0 \pm 5.0 \%$.

Calves fed $1 / 5 \mathrm{~L}$ of fresh colostrum by nipple bottle at birth, and again after $4 \mathrm{~h}$, and every $12 \mathrm{~h}$ thereafter. Calves were fed colostrums for $3 \mathrm{~d}$ then switched to milk until the end of trail ( 8 week). Calves were assigned randomly at birth to one of four treatments. Treatments included: whole milk with no additives (control), whole milk containing probiotic at $1 \mathrm{~g}$ Protexin ${ }^{\circledR}$ (multi-strain probiotic contains 7 bacteria strains and 2 yeast strains with $2 \times 10^{9} \mathrm{cfu} / \mathrm{g}$ ) per day, whole milk containing prebiotic at 4 g $\operatorname{Tipax}^{\circledR}$ (polysaccharides of saccharomyces cereviciae cell wall) per day, whole milk containing $1 \mathrm{~g}$ probiotic and $4 \mathrm{~g}$ prebiotic (synbiotic) per day. Calves received whole milk twice daily at 0700 and $1600 \mathrm{~h}$ : calf starter and water were offered $a d$ libitum throughout the trial of 60 days. Calf starter contained no growth promoters. The composition and the analyzed nutrient content of offered feeds are provided in Table 1. Starter intake was recorded daily throughout the trial. Body weight was measured at birth and thereafter at weekly interval up to 8 week of age.

\section{Sampling, measurement, and analyses}

Fecal samples were collected weekly from rectum with sterile rubber gloves and place in sterile plastic tubes with led. The samples were stored in a freezer at $-20^{\circ} \mathrm{C}$ until analysis for counts of E. coli. In vitro survival and enumeration of $E$. coli was determined according to the method of Gue et al. (2006).

Blood samples were collected from jugular veins on $\mathrm{d} 3$, 30 and 60, approximately $3 \mathrm{~h}$ after the morning feeding and transported to the laboratory. Serum was separated from blood by centrifugation at $2,000 \times \mathrm{g}$ for $10 \mathrm{~min}$. Serum was frozen at $-25^{\circ} \mathrm{C}$ till analyzed for WBC count, neutrophil, lymphocyte and monocyte concentration. Plasma samples were extracted and stored frozen for ELISA analysis of immunoglobulin G1. The ELISA analysis was described previously by Rivera et al. (2002).

Cell-mediated immune response was measured in vivo by phytohemagglutinin (PHA) skin test. On d 60, calves

Table 1. The composition and the analyzed nutrient content in the diet fed to the calves

\begin{tabular}{lc}
\hline Composition \% & 35 \\
\hline Corn & 20 \\
Barley & 25 \\
Soybean meal & 5 \\
Cotton seed meal & 1 \\
Fish meal & 9.5 \\
Bran & 0.5 \\
Salt & 2 \\
Mineral and vitamin premix & 1 \\
Calcium carbonate & 1 \\
Sodium bicarbonate & \\
Analyzed content & 87.5 \\
Dry matter $(\%)$ & 46.5 \\
Crude fiber $(\mathrm{g} / \mathrm{kg})$ & 192 \\
Crude protein $(\mathrm{g} / \mathrm{kg})$ & 11.1 \\
Calcium $(\mathrm{g} / \mathrm{kg})$ & 12.1 \\
phosphorus $(\mathrm{g} / \mathrm{kg})$ &
\end{tabular}

Provided (pp/kg), iron 25.0; manganese, 100.0; cobalt 2.5; iodine, 0.0; selenium, 0.2; vitamin A, 20,000 IU $/ \mathrm{kg}$; vitamin D, 4,000 IU/ $\mathrm{kg}$; vitamin $\mathrm{E}, 120 \mathrm{UI} / \mathrm{kg}$ 
were injected by $150 \mu \mathrm{g}$ of PHA in $0.1 \mathrm{ml}$ of PBS. The injection site was immediately posterior to the scapula. The skinfold thickness was measured before injection and 2, 4, 6 , $8,12,24$ and $48 \mathrm{~h}$ after injection using micrometric clippers.

\section{Statistical analysis}

All statistical analyses were conducted by ANOVA using the general linear models procedures of SAS (SAS Institute, 2000). Data were analyzed as a randomized complete design with calf as the experimental unit and repeated measurements. Effect of time and interaction between treatment and time were included in the model as fixed effects when blood parameters were analyzed. Results were presented as least square means with SEM. There were no significant difference between average weight of calves by Duncan test ( $p>0.10)$ at the beginning of the study, therefore no longer correction of birth weight of calves have done. Treatment effects were considered significant at $\mathrm{p} \leq 0.05$.

\section{RESULTS AND DISCUSSION}

Calf starter intakes were recorded beginning at 2 week of age because calves did not consume starter during the first week of life. Comparison of weekly dry matter intake (DMI) illustrated that there was no significant difference among treatments till the end of trial (Table 1). In most experiments which studied effects of probiotics in calves, researchers focused on a single or two strain probiotics. Quigly et al. (1992) found no significant effect of yeast probiotic on intake of starter in dairy calves. Donovan et al. (2002) reported that intake of dry starter was similar between calves fed prebiotic or control. However, Rust et al. (2000) reported increased DMI in beef steers which received lactic acid based probiotic. Michael and Abney (2001) reported no significant difference in DMI between calves received probiotic and prebiotic and control group.

Data on weekly average daily gain (ADG) indicate that calves fed synbiotic and calves fed prebiotic had consistently higher ADG than probiotic and control treatments (Table 2). At week 7 and 8, ADG was significantly greater $(\mathrm{p}<0.05)$ for synbiotic, probiotic and prebiotic treatments than control treatment. Overall, it was observed that calves fed synbiotic $(557 \mathrm{~g} / \mathrm{d})$ had greater ADG than other treatments $(p<0.05)$ and there was no significant difference between probiotic $(514 \mathrm{~g} / \mathrm{d})$ and prebiotic $(530 \mathrm{~g} / \mathrm{d})$ and between probiotic and control (489 $\mathrm{g} / \mathrm{d})$ treatments. In large intestine probiotic will start to colonize and beneficial bacteria such as lactobacillus acidophilus and enterococcus faecium will multiply, exclude the harmful bacteria and establish themselves in the digestive system. Prebiotic in the colon and large intestine
Table 2. Weekly dry matter intake $(\mathrm{g} / \mathrm{d})$ of calves fed with or without additives

\begin{tabular}{lccccc}
\hline \multirow{2}{*}{ Week } & \multicolumn{4}{c}{ Treatment } & Pooled \\
\cline { 2 - 5 } & Control & Probiotic & Prebiotic & Synbiotic & SE \\
\hline 2 & 51 & 74 & 40 & 75 & 24 \\
3 & 188 & 168 & 174 & 202 & 46 \\
4 & 530 & 573 & 519 & 604 & 51 \\
5 & 677 & 635 & 615 & 696 & 24 \\
6 & 746 & 684 & 711 & 774 & 31 \\
7 & 1,142 & 1,068 & 1,017 & 1,125 & 48 \\
8 & 1,408 & 1,385 & 1,375 & 1,432 & 35 \\
\hline
\end{tabular}

are readily fermented by these beneficial bacteria. This may result in changes in the population of beneficial microorganisms, while repressing the number of harmful bacteria. In addition, the production of VFA by bacteria fermenting prebiotics in animals may improve energy efficiency and alter intestinal morphology. These possible changes in the microbiology and chemistry of the large intestine may be responsible for improved ADG at ending weeks. It is also believed that probiotics and prebiotics can improve digestibilities of dry matter, energy, crude protein and amino acids (Li et al., 2008; Kong et al., 2008; Kong et al., 2011) and increase bioavailability of minerals in the gut. Moreover, probiotics produce water soluble vitamin B group which may improve nutrient metabolism in gut ADG in this trial were similar to those reported by Quigly et al. (1997). Lesmeister et al. (2004) reported improvement in ADG when $2 \%$ supplemental probiotic was added to a calf diet. Abe et al. (1995) administered Bifidiobacterium Pseudolongum or Lactobacillus Acidophilus in MR to neonatal from d 7 to $d 35$ of age. They reported that both probiotic improved body weight gain. In this experiment calves received a combination of probitic and prebiotic together had greater ADG than calves received probiotic or prebiotic alone, this may be due to more synergetic effects of synbiotic on stimulating beneficial microflora compared to supplementing probiotic and prebiotic alone.

Result of fecal E. coli count illustrated that calves received pro-prebiotic and synbiotic had significantly lower E. coli in feces on d 56 compared with the control treatment (Table 4). There are two proposed mechanisms by which probiotics may reduce harmful bacteria such as $E$. coli in intestinal tract and following in feces. Firstly, probiotics microorganisms produce some inhibitory substances such as organic acids, hydrogen peroxide and bacteriocins which these antimicrobial-like compounds might be active against some pathogens. Second mechanism is that of competitive inhabitation for harmful bacteria adhesion on intestinal epithelial surfaces. Elam et al. (2003) reported that lactobacillus acidophilus decreased fecal $E$. coli shedding in 
Table 3. Weekly average daily gain $(\mathrm{g} / \mathrm{d})$ of calves fed with or without additives

\begin{tabular}{lccccc}
\hline \multirow{2}{*}{ Week } & \multicolumn{4}{c}{ Treatment } & Pooled \\
\cline { 2 - 4 } & Control & Probiotic & Prebiotic & Synbiotic & SE \\
\hline 1 & 22 & 63 & 55 & 67 & 13 \\
2 & 59 & 101 & 115 & 128 & 29 \\
3 & 200 & 284 & 252 & 295 & 22 \\
4 & 507 & 596 & 612 & 635 & 35 \\
5 & 643 & 677 & 689 & 711 & 44 \\
6 & 995 & 1,018 & 1,037 & 1,125 & 43 \\
7 & $1,024^{\mathrm{b}}$ & $1,185^{\mathrm{a}}$ & $1,190^{\mathrm{a}}$ & $1,212^{\mathrm{a}}$ & 25 \\
8 & $974^{\mathrm{b}}$ & $1,149^{\mathrm{a}}$ & $1,188^{\mathrm{a}}$ & $1,269^{\mathrm{a}}$ & 38 \\
\hline
\end{tabular}

${ }^{\mathrm{a}, \mathrm{b}}$ Value with different Superscripts within a row differ significantly $(\mathrm{p}<0.05)$.

beef steers. Liu et al. (2008) in an experiment studied effects of prebiotic on fecal shedding of $E$. coli and lactobacillus in weaning pigs. They concluded that diet containing prebiotic decreased E. coli count and increase lactobacillus in the feces on d 21 compared with the control diet. Mannanoligosaccharides (MOS) prebiotic is thought to bind the lectins contained in the cell wall of certain pathogenic bacteria. This binding of the MOS to the pathogenic cell wall inactive the binding sites of the bacteria, thus they are flushed out of the GIT without causing pathogenic effects. However, Micheal and Abney (2001) observed no significant difference in fecal E. coli populations of calves received probiotic, prebiotic and control calves.

Shim (2005) reported that population of E. coli in the colon of suckling pigs which received probiotic, prebiotic and synbiotic was significantly lower compared to the
Table 4. Number of Escherichia coli (log cfu/g of wet digesta) in calves fed with or without additives

\begin{tabular}{|c|c|c|c|c|c|}
\hline \multirow{2}{*}{ Day } & \multicolumn{4}{|c|}{ Treatment } & \multirow{2}{*}{$\begin{array}{c}\text { Pooled } \\
\text { SE }\end{array}$} \\
\hline & Control & Probiotic & Prebiotic & Synbiotic & \\
\hline 7 & 7.58 & 7.44 & 7.87 & 7.61 & 0.44 \\
\hline 14 & 7.49 & 7.55 & 7.69 & 7.58 & 0.21 \\
\hline 21 & 7.53 & 7.59 & 7.71 & 7.54 & 0.12 \\
\hline 28 & 7.66 & 7.31 & 7.55 & 7.39 & 0.24 \\
\hline 35 & 7.44 & 7.55 & 7.38 & 7.41 & 0.11 \\
\hline 42 & 7.53 & 7.61 & 7.31 & 7.29 & 0.15 \\
\hline 49 & 7.65 & 7.52 & 7.38 & 7.26 & 0.33 \\
\hline 56 & $7.58^{\mathrm{a}}$ & $7.44^{\mathrm{b}}$ & $7.11^{\mathrm{b}}$ & $7.04^{\mathrm{b}}$ & 0.38 \\
\hline
\end{tabular}

${ }^{\mathrm{a}, \mathrm{b}}$ Value with different Superscripts within a row differ significantly $(\mathrm{p}<0.05)$.

control.

Data on serum and plasma biochemistry indicated that there was no significant difference in white blood cell count, neutrophil, lymphocyte and monocyte concentration and plasma IgG1 concentration at any collection period (Table 5). No treatment $\times$ time interaction was noted for white blood cell count, neutrophil, lymphocyte and monocyte concentration. This could be due to good hygienic provided to the calves that these blood parameters which related to immune system was unaffected by treatments. Shim (2005) reported that haematological traits (WBC count, neutrophil, monocyte, lymphocyte and hemoglobin) were unaffected by prebiotic, multi-strain probiotic and synbiotic in weaned pigs. However, Heinrich et al. (2002) found that immune parameters such as lymphocytes, leukocyte and neutrophils tended to increase in supplementation of synbiotic (combining lactobacillus and fructooligosaccharides)

Table 5. Blood parameters in calves fed with or without additives

\begin{tabular}{|c|c|c|c|c|c|c|}
\hline \multirow{2}{*}{ Collection day } & \multirow{2}{*}{ Blood parameters } & \multicolumn{4}{|c|}{ Treatment } & \multirow{2}{*}{ Pooled SE } \\
\hline & & Control & Probiotic & Prebiotic & Symbiotic & \\
\hline \multirow[t]{5}{*}{3} & White blood cell (number/ $\mu \mathrm{l})$ & 10,200 & 10,280 & 10,310 & 1,0340 & 188 \\
\hline & Neutrophil \% & 37 & 32 & 36 & 36 & 6 \\
\hline & Lymphocyte \% & 62 & 4 & 63 & 64 & 3 \\
\hline & Monocyte \% & 0 & 0 & 0 & 0 & 1 \\
\hline & Immunoglobulin G (mg/dl) & 1,220 & 1,148 & 1,285 & 1,347 & 259 \\
\hline \multirow[t]{5}{*}{30} & White blood cell (number/ $\mu \mathrm{l})$ & 6,100 & 6,750 & 6,500 & 6,720 & 98 \\
\hline & Neutrophil \% & 31 & 26 & 24 & 27 & 3 \\
\hline & Lymphocyte \% & 74 & 73 & 74 & 72 & 4 \\
\hline & Monocyte \% & 1 & 0 & 1 & 0 & 2 \\
\hline & Immunoglobulin G (mg/dl) & 912 & 825 & 995 & 1,065 & 118 \\
\hline \multirow[t]{5}{*}{60} & White blood cell (number/ $\mu \mathrm{l})$ & 8,840 & 8,920 & 9,010 & 8,760 & 122 \\
\hline & Neutrophil \% & 23 & 24 & 28 & 26 & 4 \\
\hline & Lymphocyte \% & 76 & 75 & 71 & 71 & 6 \\
\hline & Monocyte \% & 0 & 0 & 0 & 0 & 1 \\
\hline & Immunoglobulin G (mg/dl) & 1,012 & 942 & 1,103 & 1,133 & 0.25 \\
\hline
\end{tabular}


compared to the single administration of lactobacillus and the control in weaned pigs. Plasma IgG1 concentartion changed over the time and there was no treatment $\times$ time interaction. Although plasma IgG1 concentration tended to be higher in synbiotic and prebiotic treatments but the differences was not significant. Plasma IgG1 concentration was greater in all calves on d 3 than d 30 and 60. Plasma IgG is highest after birth because of passive transfer of colostrum antibodies, then it reduced until animal is able to produce its own antibodies (Riddell et al., 2010). It was hypothesized that addition of pro- prebiotic and synbiotic to milk would stimulate an increase in IgG levels as an antispore immune response (Hong et al., 2005). However, Morill et al. (1995) showed that probiotic supplementation in calves had no effect on immunoglobulins. Riddell et al. (2010) also showed that probiotic had no significant effect on plasma IgG1 concentration of preruminant calves. Kelly, (2004) reported that mares receiving prebiotic supplementation had higher colostrums $\operatorname{IgA}$ and $\operatorname{IgM}$ than control group, but were no significant difference between treatments for mare IgG, IgM and IgA plasma levels at any collection period. Franklin et al. (2005) reported numerically greater $\operatorname{IgG}$ and $\operatorname{IgM}$ concentration $24 \mathrm{~h}$ post calving in calves from cows supplemented with prebiotic, but the difference were not significant. Kaila et al. (1992) reported that the immune system of weaned pig was stimulated by probiotics supplementation. Deng et al. (2007) reported that dietary supplementation with polysaccharides from Semen cassiae increased: i) serum concentrations of interleukin (IL)-1, IL-2 and IL-6, as well as $\operatorname{IgG}, \operatorname{IgM}$ and $\operatorname{IgA}$; ii) expression of the IL-1 and IL-2 genes in blood mononuclear cells and lymphatic nodes. They suggested that these polysaccharides enhanced both cell-mediated immune response and the humoral immunity in the early-weaned piglets. Yin et al (2008) showed that galacto-mananan-ologosaccharid and chitosan oligosaccharide enhanced IL-1 gene expression in jejunal mucosa as well as serum levels of IL-1, IL-2, IL-6, IgG, IgM and $\operatorname{IgA}$ in piglets.

There was no significant difference between treatments in increase of skinfold thickness to intradermal injection of phytohemagglutinin (Table 6).

The skin test provides a measure of the proliferative response potential of circulating $\mathrm{T}$ lymphocytes to an injected mitogen such as phytohemagglutinin (Smits et al., 1999). Apgar et al. (1993) reported that probiotic had no effect in cell-mediated immune response of pigs. The skin test conducted in the current study to determine whether pro- prebiotic and synbiotic could improve immune response even if no significant blood parameters response was observed. Panda et al. (2007) reported probiotic had an immunoregulatory effect on cell mediated immunity and humoral immune response in poultry. Emmanuel et al.
Table 6. Effect of probiotic, prebiotic and synbiotic on skinfold response to intradermal injection of PHA

\begin{tabular}{lccccc}
\hline $\begin{array}{l}\text { Hours after } \\
\text { PHA } \\
\text { injection }\end{array}$ & Control & Probiotic & Prebiotic & Synbiotic & SE \\
\cline { 2 - 5 } & & & & & \\
\hline 2 & $4.38^{\mathrm{a}}$ & 4.31 & 4.29 & 4.35 & 0.55 \\
4 & 4.05 & 3.98 & 3.94 & 3.99 & 0.53 \\
8 & 3.27 & 3.22 & 3.32 & 3.36 & 0.45 \\
12 & 3.77 & 3.65 & 3.58 & 3.80 & 0.43 \\
24 & 2.97 & 2.84 & 2.89 & 2.93 & 0.40 \\
48 & 2.55 & 2.34 & 2.29 & 2.73 & 0.42 \\
\hline
\end{tabular}

${ }^{\text {a }}$ Skinfold increase (mm).

(2007) reported that probiotic induced an inflammatory response in feedlot steers fed high-grain diets. Kong et al. (2009), observed an increase in cellular immunity in weanling rats supplemented with Chinese Yam polysaccharide In a same experiment done by the author of the current study, humoral immune response to ovalbumin injection was tended to increased in calves received synbiotic on d 56 compared to the control and calves received multi-strain probiotic and mannano-ligosaccharide prebiotic (Mohamadi and Dabiri, 2011).

\section{CONCLUSIONS}

Addition of pro- prebiotic and symbiotic to the whole milk of dairy female calves increased ADG and reduced fecal shedding of E. coli at the ending weeks but dry matter intake and blood parameters related to immune system and cell-mediated immune response were not affected. However, when a combination of probiotic and prebiotic added to the milk a better improvement in average daily gain and more decrease in fecal E. coli was observed. The effects of proprebiotic and synbiotic on the immune system of dairy calves seems merits further research.

\section{ACKNOWLEDGEMENTS}

The authors gratefully acknowledge Behdaneh Pars Company for preparing calves and other facilities.

\section{REFERENCES}

Abe, F. and S. shimamura. 1995. Effect of administration of Bifidiobacteria and Lactic acid bacteria to newborn calves and piglets. J. Dairy Sci. 78:2838-2846.

Apgar, G. A., E. T. Kornegay, M. D. Lindemann and C. M. Wood. 1993. The effect of feeding various levels of Bifidobacterium globosum A on the performance, gastrointestinal measurements, and immunity of weaning pigs and on performance and carcass measurements of growing-finishing pigs. J. Anim. Sci. 71:2173-2179.

Amabile-Cuevas, C., M. Cardenas-Garcia and M. Ludgar. 1995. 
Antibiotic resistance. J. Anim. Sci. 83:320-332.

Cruywagen, C. W., J. Ina and L. Venter. 1995. Effect of lactobacillus acidophilus supplementation of milk replacer on preweaning performance of calves. J. Dairy Sci. 79:483-486.

Deng, Z. Y., J. W. Zhang, J. Li, Y. W. Fan, S. W. Cao, R. L. Huang, Y. L. Yin, H. Y. Zhong and T. J. Li. 2007. Effect of polysaccharides of cassiae seeds on the intestinal microflora of piglets. Asia Pac. J. Clin. Nutr. 16(Suppl 1):143-147.

Deng, Z. Y., J. W. Zhang, G. Y. Wu, Y. L. Yin, Z. Ruan, T. J. Li, W. Y. Chu, X. F. Kong, Y. M. Zhang, Y. W. Fan, R. Liu and R. L. Huang. 2007. Dietary supplementation with polysaccharides from Semen cassiae enhances immunoglobulin production and interleukin gene expression in early-weaned piglets. J. Sci. Food Agric. 87:1868-1873.

Donovan, D. C., S. T. Franklin, C. C. Chase and A. R. Hippen. 2002. Growth and health of Holstein calves fed replacer supplemented with antibiotics or Enteroguard. J. Dairy Sci. 85: 947-950.

Elam, N. A., J. F. Gleghorn, J. D. Rivera, M. L. Galyean, P. J. Defoor, M. M. Brashears and S. M. Younts-dahl. 2003. Effects of live cultures of Lactobacillus acidophilus (strains NP45 and NP51) and propionibacteroum freudenreichii on performance, carcass, and intestinal characteristics and Escherichia coli strain 0157 shedding of finishing beef steers. J. Anim. Sci. 81: 2686-2698.

Emmanuel, D. G. V., A. Jafari, K. A. Beauchemin and J. A. Z. Leedle. 2007. Feeding live cultures of Enterococcus faecium and Saccharomyces cerevisiae induces an inflammatory response in feedlot steers. J. Anim. Sci. 85:233-239.

Fevier, R., A. Francois, M. Michel, R. Pero and E. SalmonLegagneur. 1955. Antibiotic and growth. Compates Rendus DE 1’Acdemic D`Agriculture de France 41:698.

Fleige, S. W., H. H. D. Preibinger and W. P. Mayer. 2009. The immunmodulatory effect of lactulose on entereococcus faecium-fed preruminant calves. J. Anim. Sci. 87:1731-1738.

Franklin, S, T., M. C. Newman, K. E. Newman and K. I. Meek. 2005. Immune parameter of dry cows fed mannanoligosacchrides and subsequent transfer of immunity to calves. J. Dairy Sci. 88:766-775.

Fuller, R. 1989. Probiotics in man and animal. A review. Appl. Bacteriol. 66:365-378

Guo, X., D. Li, W. Lu, X. Piao and. X. Chen. 2006. Screening of Bacillus strains as potential probiotics and subsequent confirmation of the in vivo effectiveness of Bacillus subtilis MA139 in pigs. Antonie Van Leeuwenhoek 90:139-146.

Heinrichs, A. J., M. Jones and B. S. Heinrichs. 2003. Effects of mannanoligosaccharide or antibiotic in neonatal diets on health and growth of dairy calves. J. Dairy Sci. 86:4064-4069.

Hong, H. A., L. H. Duc and S. M. Cutting. 2005. The use of bacterial spore formers as probiotics. FEMS Microbiol. Rev. 29:813-835.

Huang, R. L., Y. L. Yin, G. Y. Wu, Y. G. Zhang, T. J. Li, L. L. Li, M. X. Li, Z. R. Tang, J. Zhang, B. Wang, J. H. He and X. Z. Nie. 2005. Effect of dietary oligochitosan supplementation on ileal digestibility of nutrients and performance in broilers. J. Poult. Sci. 84:1383-1388.

Huang, R. L., Y. L. Yin, M. X. Li, G. Y. Wu, T. J. Li, L. L. Li, C. B. Yang, J. Zhang, B. Wang, Z. Y. Deng, Y. G. Zhang, Z. R. Tang, P. Kang and Y. M. Guo. 2007. Dietary oligochitosan supplementation enhances immune status of broilers. J. Sci. Food Agric. 87:153-159.

Kaila, M., E. Isolauri, E. Soppi, E. Virtanen, S. Laine and H. Arvilommi. 1992. Enhancement of the circulating antibody secreting cell response in human diarrhoea by a human Lactobacillus strain. Pediatr. Res. 32:141-144.

Kaufhold, J. H., M. Hammon and J. Blum. 2000. Fructoligosaccharide supplementation: effects on metabolic, endocrine and hematological traits in veal calves. J. Vet. Med. 47:2-20.

Kelly, R. 2004. Effects of Mannanoligosaccharide supplementation on immune status of mares and their foals. MSc thesis , University of Florida. USA.

Kogan, G. and A. Kocher. 2007. Role of yeast cell wall polysaccharides in pig nutrition and health protection. J. Livest. Sci. 75:1009-1016.

Kong, X. F., G. Y. Wu, Y. P. Liao, Z. P. Hou, H. J. Liu, F. G. Yin, T. J. Li, R. L. Huang, Y. M. Zhang, D. Deng, P. Kang, R. X. Wang, Z. Y. Tang, C. B. Yang, Z. Y. Deng, H. Xiong, W. Y. Chu, Z. Yuan, M. Y. Xie and Y. L. Yin. 2007. Effects of Chinese herbal ultra-fine powder as a dietary additive on growth performance, serum metabolites and intestinal health in early-weaned piglets. Livest. Sci. 108:272-275.

Kong, X. F., G. Y. Wu, Y. L. Yin, H. J. Liu, F. G. Yin, T. J. Li, R. L. Huang, P. Kang, F. Xing, M. Z. Fan, C. B. Yang and Q. H. He. 2007. Dietary supplementation with Chinese herbal ultra-fine 3 powder enhances cellular and humoral immunity in early weaned piglets. Livest. Sci. 108:94-98.

Kong, X. F., Y. L. Yin, Q. H. He, F. G. Yin, H. J. Liu, T. J. Li, R. L. Huang, M. M. Geng, Z. Ruan, Z. Y. Deng, M. Y. Xie and G. Wu. 2008. Dietary supplementation with Chinese herbal powder enhances ileal digestibilities and serum concentrations of amino acids in young pigs. Amino Acids 37:573-582.

Kong, X. F., Y. Z. Zhang, Y. L. Yin, G. Y. Wu, H. J. Zhou, Z. L. Tan, F. Yang, M. J. Bo, R. L. Huang, T. J. Li and M. M. Geng. 2009. Chinese Yam polysaccharide enhances growth performance and cellular immune response in weanling rats. J. Sci. Food Agric. 89:2039-2044.

Kong, X. F., G. Y. Wu and Y. L. Yin. 2011. Roles of phytochemicals in amino acid nutrition. Front. Biosci. S3:372384

Lesmeister, K. E. A. Heinrichs, and M. T. Gabier. 2004. Effects of supplemental yeast culture on rumen development, growth character and blood parameters in neonatal dairy calves. J. Dairy Sci. 87:1832-1839.

Li, L. L., Z. P. Hou, C. B. Yang, G. Y. Wu, R. L. Huang, Z. R. Tang, J. H. Gong, H. Yu, T. J. Li, X. F. Kong, C. F. Pan, J. Deng, X. Q. Wang, G. Yin and Y. L. Yin. 2008. Effects of probiotic supplementation on ileal digestibility of nutrients and growth performance in 1-d-old to 42-d-old broilers. J. Sci. Food Agric. 88:135-142.

Liu, P., X. S. Piao, S. W. Kim, L. Wang, Y. B. Shen, H. S. Lee and S. Y. Li. 2008. Effects of chito-oligosaccharides supplementation on the growth performance, nutrient digestibility, intestinal morphology, and fecal shedding of Escherichia coli and lactobacillus in weaning pigs. J. Anim. Sci. 86:2609-2618.

Miguel, J. C., S. L. Rodriguez-Zas and J. E. Pettigrew. 2004. Efficacy of a mannan oligosaccharide (Bio-Mos ${ }^{\circledR}$ ) for 
improving nursery pig performance. J. Swine Health Prod. 12: 296-307.

Michael, D. and B. S. Abney. 2001. Effects of feeding direct-fed microbials and prebiotics on receiving calf performance, health, and fecal shedding of pathogens. Msc thesis, Texas Tech University, August 2001.

Mohamadi, P. and N. Dabiri. 2011. Effects of probiotic, prebiotic and synbiotic on performance and humoral immune response of female suckling calves. In proceeding of the 62nd annual meeting of the European Association for Animal Production. Stavanger, Norway. 29 August to 2 September, 2011. p. 204.

Morrill, J. L., M. Morrill and A. M. Feyerherm. 1995. Plasma protein and probiotic as ingredients in milk replacer. J. Dairy Sci. 78:902-907.

Okamoto, Y., A. Inoue, K. Miyatake, K. Ogihara, Y. Shigemasa and S. Minami. 2003. Effects of chitin/chitosan and their oligomers/monomers on migrations of macrophages. Macromol. Biosci. 3:587-590.

Panda, A. K., S. S. Rama-Rao, M. V. Raju and S. S. Sharma. 2007. Effect of probiotic feeding on egg production and quality, yolk cholesterol and humoral immune response of white leghorn layer breeders. J. Sci. Food Agric. 88:43-47.

Piddock, L. J. V. 1996. Does the use of antimicrobial gent in veterinary medicine and animal husbandry select antibiotic resistant bacteria that can infect man and compromise antimicrobial chemotherapy? J. Antimicrob. Chemother. 38:1-3.

Quigley, J. D. L., B. Wallis, H. Downlow and R. N. Heitman. 1992. Sodium bicarbonate and yeast culture effects on ruminal fermentation, growth and intake in dairy calves. J. Dairy Sci. 75:3531-3538.

Quigley, J. D., J. J. Drewry, L. M. Murray and S. J. Ivey. 1997. Body weight gain, feed efficiency, and fecal scores of dairy calves in response to galactosyl-lactose or antibiotics in milk replacers. J. Dairy Sci. 80:1751- 1754.

Riddell, J. B., A. J. Gallegos, D. L. Harmon and K. R. Mcleod. 2010. Addition of a Bacillus based probitic to the diet of preruminant calves: influence on growth, health, and blood parameters. Intern. J. Appl. Res. Vet. Med. 8:78-85.

Rolfe, R. D. 2000. The role of probiotic cultures in the control of gastrointestinal health. J. Nutr. 130:398S-402S.
Rivera, J. D., G. C. Duff, M. L. Galyean, D. A. Walker and G. E. Nunnery. 2002. Effects of supplemental vitamin E on performance, health and humoral immune response of beef cattle. J. Anim. Sci. 80:933-941.

Rust, S. R., K. Metz and D. R. Ware. 2000. Effects of Bovamine ${ }^{\mathrm{TM}}$ rumen culture on the performance and carcass characteristics of feedlot steers. J. Anim. Sci. 78(Supp2):83(Abstr.).

SAS Institute. 2000. SAS user's guide. Statistics, version 8.01. Cary, NC: SAS Institute.

Shim, S. B. 2005. Effects of prebiotics, probiotics and synbiotics in the diet of young pigs. Ph.D. Thesis. Animal Nutrition Group, Wageningen Institute of Animal Sciences, Wageningen University and Research Center, Wageningen, Netherlands.

Smits, J. E., G. R. Bortolotti and J. L. Tella. 1999. Simplifying the phytohaemagglutinin skin-testing technique in studies of avian immunocompetence. Funct. Ecol. 13:567-572.

Tang, Z. R., L. Y. Yin, C. M. Nyachoti, R. L. Huang, T. J. Li, C. B. Yang, X. J. Yang, J. Gong, J. Peng, D. S. Qi, J. J. Xing, Z. H. Sun and M. Z. Fan. 2005. Effect of dietary supplementation of chitosan and galacto-mannan-oligosaccharide on serum parameters and the insulin like growth factor-I mRNA expression in early-weaned piglets. Domest. Anim. Endocrinol. 28:430-441.

Timmerman, H. M., L. Mudler, H. Everts and D. C. Vanespan. 2005. Health and growth of veal calves fed milk replacer with or without probiotics. J. Dairy Sci. 75:894-899.

Windschitl, M., M. Paul, M. Kirsten and J. Donald. 1991. "Growth performance of Holstein dairy calves supplemented with a probiotics". Agricultural and Forestry Experiment Station School of Agriculture and Land Resources Management. University of Alaska Fairbanks. April 1991.

Yin, Y. L., Z. R. Tang, Z. H. Sun, Z. Q. Liu, T. J. Li, R. L. Huang, Z. Ruan, Z. Y. Deng, B. Gao, L. X. Chen, G. Y. Wu and S. W. Kim. 2008. Effect of galacto-mannan-oligosaccharides or chitosan supplementation on cytoimmunity and humoral immunity response in early-weaned piglets. Asian-Aust. J. Anim. Sci. 21:723-731.

Yoon, I. K. and M. D. Stern. 1995. Influence of direct-fed microbials on ruminal microbial fermentation and performance of ruminants: A review. Asian-Aust. J. Anim. Sci. 8:533-555. 